\title{
Organogenesis from Mature Pecan Cotyledons and Embryonic Axes
}

\author{
Ahmed A. Obeidy and M.A.L. Smith \\ Department of Horticulture, University of Illinois, 1201 South Dorner, \\ 1021 Plant Sciences Laboratory, Urbana, IL 61801-4720
}

Additional index words. adventitious roots, anatomy, Carya illinoinensis, embryo culture, in vitro

\begin{abstract}
The regenerative capacity of mature pecan [Carya illinoinensis (Wangenh.) K. Koch] embryonic tissues was demonstrated after pretreating mature nuts to eliminate associated endogenous contaminants. Cultured cotyledon segments were induced to form adventitious roots in a medium with $50 \mu \mathrm{M}$ NAA. A regeneration medium with $20 \mu \mathrm{M} \mathrm{BA}$ and $5 \mu \mathrm{M}$ IBA stimulated prolific axillary shoot production from the embryonic axis without causing cotyledon abscission. Cotyledon retention was essential for shoot initiation and long-term development. Eighty-five percent of the shoots emerging from embryonic axes formed at the cotyledonary nodes. Thirty percent of the microshoots rooted on an auxin-free medium after preculture in a medium with $20 \mu \mathrm{M}$ IBA. TDZ (25 $\mu \mathrm{M})$ stimulated callus production from the cotyledonary nodes and radicles. Adventitious buds emerged on the callus surface and internally in callus. Chemical names used: $a$-naphthaleneacetic acid (NAA); 6-benzylaminopurine (BA); indole-3-butyric acid (IBA); N-phenyl-N'-1,2,3-thidiazol-5-ylurea (TDZ)
\end{abstract}

Developing efficient, practical pecan regeneration strategies would broaden the opportunities for in vitro germplasm manipulation and expedite advances in crop improvement research. However, several authors have reported that only immature pecan explants respond to in vitro culture. Proliferation using pecan microcuttings derived from seedlings has been attempted, but shoot formation has been infrequent (Hansen and Lazarte, 1984; Wood, 1982). Somatic embryogenesis has been accomplished only from immature zygotic embryos of several cultivars (Merkle et al., 1987; Wetzstein et al., 1988, 1989; Yates and Reilly, 1990). Various research groups have indicated that developmental responses and regenerative capacity are diminished as nuts mature (Wetzstein et al., 1989; Yates and Reilly, 1990; Yates and Wood, 1989). The need for immature fruit constrains research in terms of experiment scheduling, seasonal restrictions, the need to have adult nut-bearing trees near the laboratory that are hardy in that climate, and replication delays. Harvested, mature pecan nuts would be a more convenient, practical, and readily available explant source for horticultural researchers, and would allow year-round sampling for in vitro research on this species.

We suspected that the lack of progress with mature tissues may be due in part to inherent contamination caused by a persistent internal fungus associated with mature pecan nuts. In previous studies, this fungus could not be

Received for publication 18 June 1992. Accepted forpublication 12 Nov. 1992. We thank Z. Carothers for his advice on interpreting the anatomical sections. The cost of publishing this paper was defrayed in part by the payment of page charges. Under postal regulations, this paper therefore must be hereby marked advertisement solely to indicate this fact. eliminated by sterilization procedures without disturbing explant viability (Obeidy and Smith, 1990). In this study, we used a medium with low water availability to yield contaminant-free embryo explants from mature nuts. From these explants, we successfully regenerated roots from mature pecan cotyledons and proliferated shoots and roots from mature zygotic embryonic axes.

Mature, dormant 'Stuart' pecan nuts were purchased from a commercial sheller (Peebles Pecan Co., Starkville, Miss.) and stored for at least 30 days at $4 \mathrm{C}$ before being used. Unshelled nuts were treated with $95 \%$ ethanol for $5 \mathrm{~min}$, then with a $5.25 \%$ sodium hypochlorite solution and $0.1 \%$ polyoxyethylene sorbitan mono-oleate (Tween 20; Sigma Chemical Co., St. Louis) for $3 \mathrm{~h}$ to surface-disinfect and several replacements of sterile, distilled water and held in the final rinse for $2 \mathrm{~h}$. Finally, nuts were shelled aseptically using a nut cracker that had been sterilized in an autoclave for $1 \mathrm{~h}$. Each nut shell was cracked initially from the basal end to avoid breaking the embryo.

The basal medium for cotyledon and embryo cultures contained MS salts (Murashige and Skoog, 1962); (per liter) $30 \mathrm{~g}$ sucrose, 2 $\mathrm{mg}$ glycine, and $50 \mathrm{mg}$ ascorbic acid; and a vitamin mixture (Staba, 1962). The medium was adjusted to $\mathrm{pH} 5.7$ and dispensed at $50 \mathrm{ml} /$ GA7 vessel (Magenta Corp., Chicago). Axenic cultures were obtained after 30 days of preculture on medium with low water availability, induced by a $1.5 \%$ agar concentration (Obeidy and Smith, 1990) that eliminated fungal contamination, followed by transfer to the same medium with normal water status $(0.7 \%$ agar). Both initial (low water availability) and final media contained the same plant growth regulators (PGRs) and other components in each treatment. To test for root organogenesis soften the shells. Treatednuts were rinsed with in cotyledon cultures, cotyledons were detached at the embryonic axes. Each cotyledon was divided perpendicularly into six segments and cultured in $80 \mathrm{ml}$ of regeneration medium with $0,3,30,50$, and $60 \mu \mathrm{M}$ NAA. There were 30 vessels per treatment and six plant segments per vessel.

In separate experiments, the basal ends of shelled, intact embryos were inserted vertically into $60 \mathrm{ml}$ of the regeneration medium. Small depressions were precut into the surface of the agar medium with a scalpel to minimize medium surface disturbance during embryo insertion. After screening a wide range of auxincytokinin combinations representing distinct molar ratios of auxin and cytokinin, we cultured 50 explants on each of six PGRs. A medium containing no PGR was the control. Media designed to induce proliferation from axillary buds contained (in $\mu \mathrm{M}$ ) $0 \mathrm{IBA} / 40 \mathrm{BA}, 5 \mathrm{IBA} /$ $40 \mathrm{BA}$, and $5 \mathrm{IBA} / 20 \mathrm{BA}$. Media specifically formulated to induce adventitious buds included (in $\mu \mathrm{M}$ ) 0 IBA/25 TDZ and 5 IBA/20 BA.

All vessels were sealed with parafilm and placed in a growth chamber in darkness at 33C. After being transferred to medium with normal water status (4 weeks) as described above, whole embryo cultures were placed under a $65-\mu \mathrm{mol} \cdot \mathrm{m}^{-2} \cdot \mathrm{s}^{-1}$ continuous photosynthetic photon flux provided by cool-white fluorescent lamps. Cotyledon cultures were examined after 2 additional weeks to determine rooting frequency and number of roots per segment. After 4 weeks under light, embryo cultures were examined to record shoot development and the incidence of cotyledon abscission.

Axillary shoots from the embryonic axes were stripped of lower leaves and inserted into test tubes containing 1) $10 \mathrm{ml}$ of a medium with $7.5 \mu \mathrm{M}$ IBA, a lower sucrose concentration (15 g.liter ${ }^{-1}$, and half-strength MS salts (control) or 2) the same medium supplemented with 5 or $10 \mu \mathrm{M} 5$-hydroxy- 1,4-naphthoquinone (juglone), 2-hydroxy-1,4-naphthoquinone, 1,4-naphthoquinone, or hydroquinone. Cultures were kept in darkness for 1 week, then exposed to light. In subsequent rooting trials, microshoots were inserted into a medium with $20 \mu \mathrm{m}$ IBA, kept in darkness for 1 week, then transferred to an auxin-free medium and into light as described above. Fifty replicates were evaluated in each rooting treatment after 5 weeks under light. Rooted plants were then transplanted into a moist, sterile 1 soil : 1 peat $: 1$ perlite mixture (by volume) contained in clean, surface-disinfected 1100 -ml plastic pots and placed under intermittent mist $(3 \mathrm{sec} / 5$ min) on a greenhouse bench. After 1 week under mist, plants were transferred to a greenhouse bench with no mist.

In separate experiments, 40 embryo axes and 80 whole embryos were cultured in a medium with $20 \mu \mathrm{M}$ BA, $5 \mu \mathrm{M}$ IBA, and a high agar concentration, as described above. After 4 weeks, the embryonic axes and half of the intact embryos were subcultured to a medium with a lower agar concentration (higher water availability), as described. The embryo axes of 
the remaining whole embryos were subcultured to a new medium.

Statistical analyses. Mean numbers of roots from cotyledon explants under various NAA concentrations were analyzed using polynomial regression analysis. Mean shoot numbers from embryonic axes with various auxin-cytokinin ratios were separated using LSD at $\mathrm{P}=$ 0.05 .

For histological studies, cotyledon segments with emerging roots and callus samples that had developed adventitious buds at the cotyledonary nodes and radicles were fixed in 1 formalin : 1 acetic acid : 18 ethanol. Samples were dehydrated through a tertiary butyl alcohol series and embedded in Paraplast tissue embedding medium (Monoject Scientific, St. Louis) with a 56C melting point. Tissues were softened by soaking them in water for 3 days before sectioning. Sections (12 pm) were prepared on a rotary microtome (Spencer model 820; American Optical Co., Buffalo, N.Y.) Microtome sections were then affixed to glass slides with Haupt's adhesive (Haupt, 1930) and double-stained with safranin-fast green (Jensen, 1962, Johanson, 1940). Sections were examined using an inverted microscope (Nikon Diaphot; Nikon Instrument Division, Garden City, N.Y.).

Sixty-three percent of the cultured cotyledon segments formed adventitious roots on a medium with $50 \mu \mathrm{M} \mathrm{NAA}$, there was an average of 18 roots per explant (Table 1). No response was observed on a medium without NAA. Higher NAA concentrations $(60 \mu \mathrm{M})$ lowered rooting frequency and number of roots formed per explant. The number of cotyledon segments developing roots and rooting frequency varied according to the segment's position on the cotyledon. Cotyledon explants taken from the basal part of the cotyledons developed nearly twice as many roots as explants taken from the top. Also, roots regenerating from basal explants were larger and thicker than those emerging from top or middle cotyledon segments. Roots did not exhibit normal geotropism, but grew freely in all directions.

Histological examination revealed that adventitious roots initiated and developed from, the cotyledons. in a specific developmental sequence (Fig. 1). First, some storage parenchyma cells became meristematic and produced callus (Fig. 1A). Within the callus, tracheary elements differentiated to form $x y$ -

Table 1. Adventitious root formation on mature cotyledonary pecan explants at various NAA concentrations. No rooting was observed in the absence of NAA.

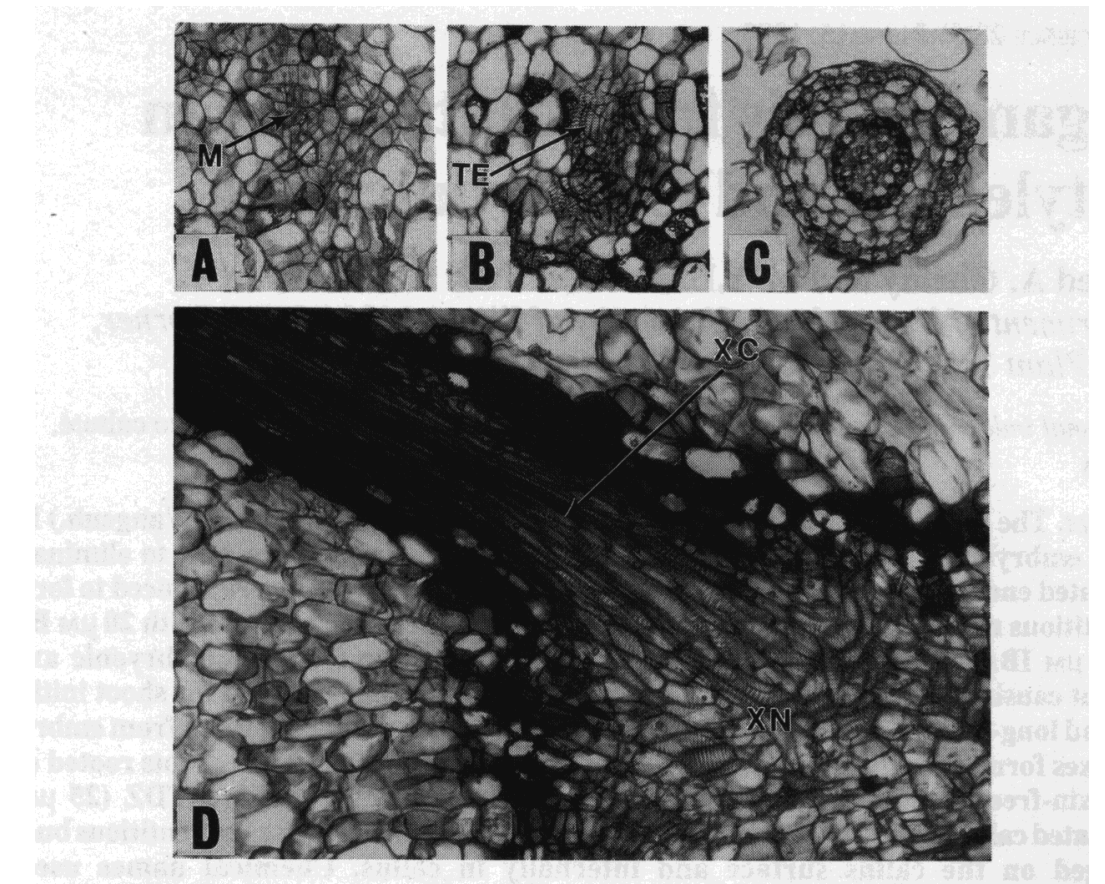

Fig. 1. Ontogenetic development of adventitious roots from mature pecan cotyledons. (A) Meristematic cells (M) resulted from dedifferentiation of cotyledon storage parenchyma. Divisions of these meristematic cells yielded internal callus masses. (B) Tracheary elements (TE), differentiated in the internal callus, forming xylem nests. Adventitious root primordia initiated from these callus xylem nests. (C) Crosssection of the buried part of an emerged adventitious root. Parenchyma cells surrounding the root were destroyed during root penetration. (D) Xylem connections (XC) have developed between a callus xylem nest $(\mathrm{XN})$ and an emerged adventitious root. Magnification $\mathrm{x} 213$.

lem nests (Fig. 1B), and adventitious root primordia initiated as a result of organized directional growth of cells from meristematic cells in the callus xylem nests. Adventitious root primordia then grew outward, penetrating the internal callus and the cotyledon's storage parenchyma tissues. Finally, xylem connections between the root primordia and the xylem nests became established as the primordia elongated and eventually emerged at the cotyledon explant surface (Fig. $1 \mathrm{C}$ and D).

Adventitious root formation from walnut (Juglans regia L.) (another member of the Juglandaceae) cotyledons has been noted previously (Jay-Allemand et al., 1991; Rodriguez, 1982). However, although limited rooting from callused cotyledonary pecan segments has been observed (Yates and Reilly, 1990), experiments to induce rooting from mature cotyledonary segments have never been reported, and the ontogeny of adventitious root formation has not been described. As in pecan stem cuttings, adventitious roots emerging from cotyledons were associated with differentiating vascular tissues (Brutsch et al., 1977). Efficient in vitro root regeneration schemes may be used to study factors that control pecan rooting and the interactions of in vitro pecan roots with soil organisms.

IBA and BA were needed to maximize shoot proliferation from axillary buds on the embryonic axes of pecan explants (Table 2). The medium with $5 \mu \mathrm{M}$ IBA and $20 \mu \mathrm{M} \mathrm{BA}$ encouraged shoot initiation of an average of 45 individual shoots per initial explant (Fig. 2 ); $\approx 85 \%$ of these shoots developed at the cotyledonary nodes. Other BA and IBA com-
Table 2. Effect of growth regulators on shoot development and cotyledon abscission from embryonic axes.

\begin{tabular}{lcc}
\hline \hline IBA/BA & $\begin{array}{c}\text { Explants } \\
\text { forming } \\
\text { shoots } \\
(\mathrm{Mo})\end{array}$ & $\begin{array}{c}\text { Embryos with } \\
\text { abscised } \\
\text { cotyledons } \\
(\%)\end{array}$ \\
\hline $0 / 0$ & $3 \mathrm{c}^{\mathrm{z}}$ & 0 \\
$0 / 40$ & $8 \mathrm{c}$ & 64 \\
$5 / 40$ & $34 \mathrm{~b}$ & 34 \\
$5 / 20$ & $45 \mathrm{a}$ & 0 \\
\hline
\end{tabular}

${ }^{2}$ Mean separation for number of shoots by LSD, $P=$ 0.05 .

binations resulted in lower shoot counts, possibly due to cotyledon abscission during the early weeks of culture (Table 2). In previous experiments, micropropagation has been attempted using microcuttings excised from pecan seedling explants; however, low proliferation rates (1.5 plantlets/explant) (Hansen and Lazarte, 1984) or profuse culture contamination (Wood, 1982) was reported. Proliferation from immature pecan embryos has also been reported; however, the rate was not stated (Yates and Wood, 1989). In contrast, high shoot proliferation rates from mature explants were obtained in the present tests without interference due to explant contamination.

The cotyledons seemed to be needed to induce shoot growth and maintain shoot development from embryonic axes. When cotyledons were excised before embryos were cultured, the isolated embryonic axes did not develop any shoots. When cotyledon excision was delayed until after 4 weeks of culture, $\approx 12$ 


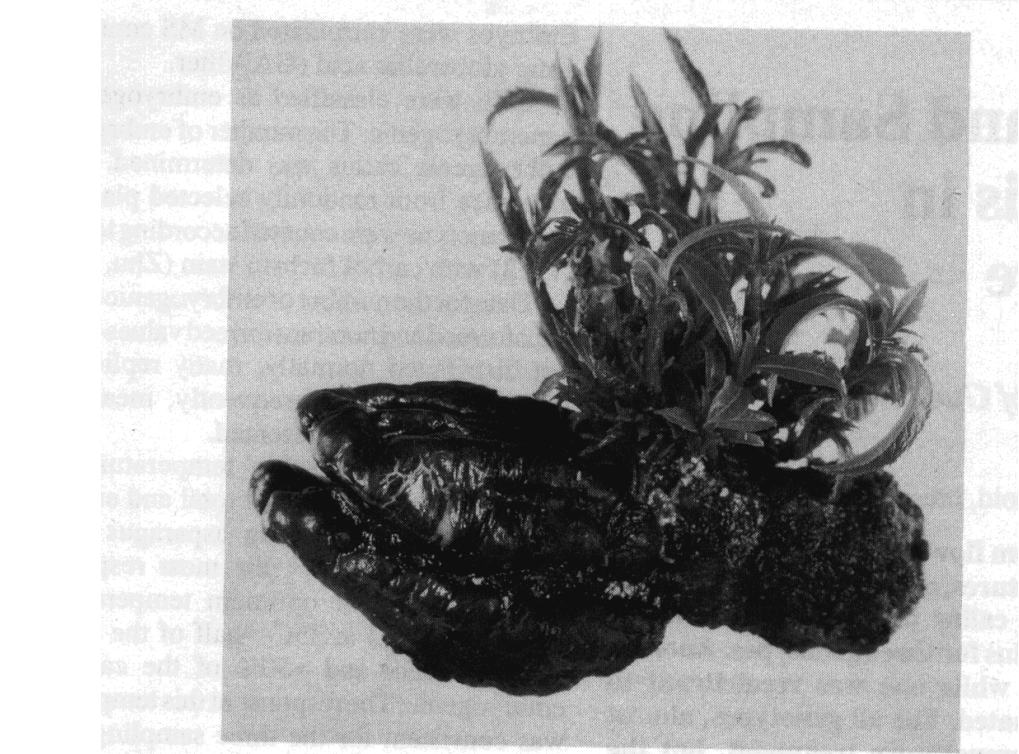

Fig.2 Shoots developed from mature pecan embryo axes in a medium with $5 \mu \mathrm{M}$ IBA and $20 \mu \mathrm{M}$ BA.

shoots developed per embryo axis. These shoots failed to survive an additional 4 weeks in vitro. When intact embryo explants were cultured (cotyledons not excised), an average of 42 shoots developed per explant. These results imply that factors supplied by the cotyledons may be needed to support shoot morphogenesis from the embryonic axes.

Thirty percent of the microshoots successfully rooted on an auxin-free medium if first precultured on a medium with $20 \mu \mathrm{M}$ IBA in darkness for 1 week. Although naphthoquinone, juglone, and hydroquinone have enhanced the in vitro rooting response of several species (Jay-Allemand et al., 1989), they did not improve the rooting response of pecan microshoots in these tests (control, 26\%; hydroquinone, $18 \%$; the rest intermediate). Rooted plantlets were transplanted successfully and became acclimated to the greenhouse environment with $\approx 100 \%$ efficiency. After 6 weeks in the greenhouse, all acclimated plants produced new vegetative growth.

TDZ-induced adventitious buds from callus developed at the cotyledonary nodes and radicles of all of the cultured explants. Adventitious buds developed mostly at the callus

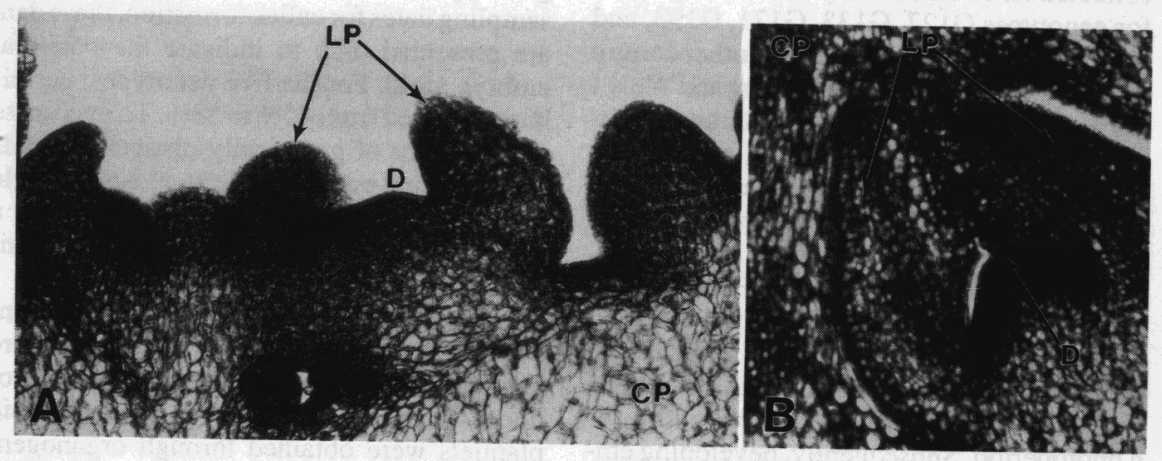

Fig. 3. Organogenesis as induced by $25 \mu \mathrm{M}$ TDZ. $\mathrm{CP}=$ callus parenchyma, $\mathrm{D}=$ dome, $\mathrm{LP}=$ first two leaf primordia. (A) Adventitious buds developed at the callus surface. (B ) An adventitious bud developed internally in the callus. Magnification $\times 195$. maintained regenerative capacity (data not shown). Since there is a clear association of endophytic fungi with mature pecan nuts (Hanlin and Blanchard, 1974; Obeidy and Smith, 1990), it is possible that fungal contaminants may have affected the response of mature explants in these previous experiments.

\section{Literature Cited}

Brutsch, M.O., P. Allan, and B.N. Wolstenholme. 1977. The anatomy of adventitious root formation in adult phase pecan [Carya illinoensis (Wang) K. Koch] stem cuttings. Hort. Res. 17:23-31.

Hanlin, R.T. and R.O. Blanchard. 1974. Fungi associated with developing pecan fruits. Bul. Georgia Acad. Sci. 32:68-75.

Hansen, K. and J.E. Lazarte. 1984. In vitro propagation of pecan seedlings. HortScience 19:237239.

Haupt, L.R. 1930. Biological field work. Color fixing solution. Gen. Biol. Supply House, Chicago.

Jay-Allemand, C.,V. DePons, P. Doumas, P. Capelli, L. Sossountzov, and D. Cornu. 1991. Formation de racines in vitro à partir de cotylédons de noix (Juglans sp.): Un modèle d'étude de la rhizogénèse chez les espèces ligneuses. III. Comptes Rendus de l'Academie des Sciences, Paris. 312:369-375.

Jay-Allemand, C., G. Keravis, J.M. Lancelin, and D. Cornu. 1989. Naphtoquinones and flavonols. Compounds associated with rejuvenation and involved on in vitro organogenesis of walnut. Proc. MHLVMatrise de la Morphogenese Conf., 19-20 Sept. 1989, Aix-Les-Bain, France. p. 50.

Jensen, W.A. 1962. Botanical histochemistryPrinciples and practice. W.H. Freeman, San Francisco.

Johansen, D.A. 1940. Plant microtechnique. McGraw-Hill, New York.

Merkle, S.A., H.Y. Wetzstein, and H.E. Sommer. 1987. Somatic embryogenesis in tissue cultures of pecan. HortScience 22:128-130.

Murashige, T. and F. Skoog. 1962. A revised medium for rapid growth and bioassays with tobacco tissue cultures. Physiol. Plant. 15:473497.

Obeidy, A.A. and M.A.L. Smith. 1990. Establishing axenic cultures from mature pecan embryo explants on media with low water availability. Plant Cell Rpt. 9:463-465.

Rodríguez, R. 1982. Callus initiation and root formation from in vitro culture of walnut cotyledons. HortScience 17:195-196.

Staba, E.J. 1962. Production of cardiac glycosides by plant tissue culture. 1 . Nutritional requirements in tissue cultures of Digitalis lanata and Digitalis purpurea. J. Pharm. Sci. 51:249-254.

Wetzstein, H.Y., J.R. Ault, and S.A. Merkle. 1989. Further characterization of somatic embryogenesis and plantlet regeneration in pecan (Carya illinoensis). Plant Sci. 64: 193-201.

Wetzstein, H.Y., S.A. Merkle, J.R. Ault, and H.E. Sommer. 1988. Somatic embryogenesis in pecan (Carya illinoensis). Southern Assn. Agr. Scientists Bul. Biochem. Biotechnol. 1:64-68.

Wood, B.W. 1982. In vitro proliferation of pecan shoots. HortScience 17:890-891.

Yates, I.E. and C.C. Reilly. 1990. Somatic embryogenesis and plant development in eight cultivars of pecan. HortScience 25:573-576.

Yates, I.E. and B.W. Wood. 1989. Organogenesis from immature pecan embryonic axes in vitro. J. Amer. Soc. Hort. Sci. 114:1025-1029. 